\title{
Correspondence
}

\section{Appeal for necropsy material from human amblyopes for morphological study}

SiR, Basic research in the medical sciences does not always seem to have direct consequences for the clinician. However, sometimes the relationships may be close. One area in which this may be true is the study of experimental amblyopia.

Since the work of Wiesel and Hubel in 1963 it is known that there are easily detectable and measurable morphological changes in the lateral geniculate nuclei of animals deprived of normal vision in their early postnatal life. Since then much work has been devoted to the study of the changes in the visual cortex and the lateral geniculate nucleus after visual deprivation by lid suture, experimental strabismus, or anisometropia, changes that are probably similar to those underlying amblyopia in man. From this work have come many basic concepts of direct clinical relevance, such as the very short time o visual deprivation necessary in the early weeks of life that cause severe central nervous changes, and the importance of early intervention if the situation is to be rectified.

We have been involved, along with many others, in research in experimental amblyopia, particularly in the monkey, which is probably the animal most comparable to man. We are struck that, to our knowledge, no case of human amblyopia has been studied post mortem using the techniques available to the experimental scientist. If we are to correlate animal results with possible clinical consequences it is vital to try to pursue such a study.

What is needed is collaboration between the ophthalmologist, the pathologist, and the basic scientist to obtain specimens from the brains of human amblyopes. One reason that this has been so difficult to accomplish in the past is that amblyopia is not a fatal disease. The chances are that the amblyope will die under circumstances totally unrelated to ophthalmological problems. Even if a necropsy is performed, the old eye pathology is likely to be forgotten. However, if ophthalmologists could be made aware of the need to obtain brain tissue from amblyopes, even years after the end of their treatment, perhaps our aim could be fulfilled.

We therefore appeal to the ophthalmologist to notify the pathologist if one of his amblyopic patients should come to necropsy, and to the pathologist to try to ascertain whether cases he sees have a history of amblyopia. Of particular interest, in addition to cases of strabismic amblyopia, would be brain specimens from patients with ocular occlusion with an onset during infancy, such as caused by congenital or infantile cataracts, tumours of the lids, corneal opacification, or any other cause. If such material were to become available, simple fixation of the posterior thalamus including the lateral geniculate nuclei and of the occipital lobes including the visual cortex in $10 \%$ formalin would suffice for our purposes.
If you can help, please contact one of the undersigned, who will be happy to give you more details of this project.

LAURENCE J. GAREY, Institute of Anatomy, Rue du Bugnon 9, 1011 Lausanne, Switzerland.

(Tel. (021) 2322 62.)

GUNTER K. VON NOORDEN, Baylor College of Medicine, Department of Ophthalmology, Texas Children's Hospital, PO Box 20269, Houston, Texas 77025, USA. (Tel. (713) 791-3183.)

\section{Notes}

\section{International Optometric and Optical League}

The 53rd congress of the IOOL will be held in Nagoya, Japan, on 26-30 May 1980. Details from the Secretariat, c/o Simul International Inc., Kowa Building No. 9. 1-8-10, Akasaka, Minato-ku, Tokyo 107, Japan.

\section{Glaucoma up to date}

The annual conference of the Glaucoma Service of the Wills Eye Hospital will be held on 6-7 June 1980. Further details from Dr K. Benjamin, c/o Glaucoma Service, Wills Eye Hospital, 1601 Spring Garden Street, Philadelphia, Pa 19130, USA.

\section{Canadian Ophthalmological Society}

The 43rd Annual Meeting will be held in Vancouver, British Columbia, Canada, on 8-11 June 1980 at the Hotel Vancouver. The principal speakers will be $\mathrm{Dr}$ Donald Gass, Miami; Dr Alston Callahan, Birmingham, Alabama; Professor Barrie Jones, London; and Dr Andrea Cibis-Tongue, Portland, Oregon. Details from PO Box 8844, Ottawa, Ontario, Canada K1G 3G2.

\section{International Society for Contact Lens Research}

The first scientific meeting of this society will be held at the Royal College of Surgeons, London, on 5-6 September 1980. All who have an interest in research and wish to attend or participate should write as soon as possible to $\mathrm{Mr}$ Montague Ruben, Moorfields Contact Lens Department, Cayton Street, London EC1. Details of membership can be obtained at the same time.

\section{Lens implants}

The United Kingdom Intraocular Implant Society will hold its autumn meeting at the Manor House Hotel, Moretonhampstead, Devon, on 1-3 October 1980. It will include the Rayner lecture and video demonstrations of lens implantation. Details from $\mathrm{Mr} \mathrm{W}$. J. Rich, West of England Eye Infirmary, Magdalen Street, Exeter. 